\title{
CONSIDERAÇÕES SOBRE A IMPORTÂNCIA DA COMPETÊNCIA INTERPESSOAL NO REPERTÓRIO COMPORTAMENTAL DE GESTORES ORGANIZACIONAIS
}

\begin{abstract}
CONSIDERATIONS ABOUT THE IMPORTANCE OF INTERPERSONAL COMPETENCE IN THE BEHAVIORAL REPERTOIRE OF ORGANIZATIONAL
\end{abstract} MANAGERS

\author{
Liz Anne de Souza Sampaio e Silva ${ }^{1}$ \\ Edward Goulart Júnior ${ }^{2}$ \\ Mário Lázaro Camargo ${ }^{3}$
}

\section{RESUMO}

O processo de transformação que vem ocorrendo no mundo do trabalho vai exigir das lideranças e das organizações uma participação mais efetiva, principalmente na direção de sensibilizar pessoas para entenderem, aceitarem e conviverem com essas transformações. $\mathrm{O}$ estabelecimento de interações satisfatórias, especialmente nas relações hierárquicas, torna-se estratégico dentro dos ambientes de trabalho, tanto para otimizar as tarefas e resultados como para favorecer a presença de um clima favorável de trabalho. Essas interações satisfatórias e direcionadas para atender demandas atuais e novas vão exigir das lideranças a presença de competências comportamentais bem desenvolvidas, dentre as quais a competência interpessoal ganha papel de destaque. O presente ensaio teórico tem como objetivo discorrer sobre a importância da competência interpessoal no repertório das lideranças organizacionais visando atender as novas demandas que se apresentam no ambiente de trabalho. Pretende também tecer considerações acerca da importância do desenvolvimento da competência interpessoal em todos os profissionais, com destaque para os cargos de liderança, apresentando algumas possíveis ações nessa direção. Para fomentar a discussão do ensaio apresentado, utilizamos artigos e livros presentes nos mais importantes periódicos especializados e indexadores eletrônicos, a saber: Periódicos Eletrônicos em Psicologia (PePSIC), Scientific Electronic Library Online (SciELO), Centro Latino-Americano e do Caribe de Informação em Ciências da Saúde (BIREME), LILACS, Banco de Teses da CAPES, Periódicos CAPES e Google Scholar. A pertinência temática em relação ao objeto de estudo escolhido foi o principal critério para a seleção dos artigos e capítulos de livros considerados no estudo.

PALAVRAS-CHAVE: Desenvolvimento de Lideranças; Competência Interpessoal; Habilidades Sociais Profissionais; Psicologia Organizacional e do Trabalho.

\footnotetext{
${ }^{1}$ Psicóloga, Graduada em Formação do Psicólogo pela Faculdade de Ciências da Unesp, campus de Bauru-SP. Atua na área de Psicologia Organizacional e do Trabalho.liz_sampaio@hotmail.com

${ }^{2}$ Professor assistente doutor do Departamento de Psicologia da Faculdade de Ciências da Unesp, campus de Bauru. Doutor em Psicologia (USP), Mestre em Psicologia e Sociedade (Unesp). Membro do Grupo de Pesquisa CNPq-Unesp "Psicologia Organizacional e do Trabalho". edward.goulart@unesp.br

${ }^{3}$ Professor assistente doutor do Departamento de Psicologia e credenciado no Programa de Pós-Graduação em Psicologia do Desenvolvimento e Aprendizagem da Faculdade de Ciências da Unesp, campus de Bauru. Doutor em Psicologia (USP), Mestre em Psicologia e Sociedade (Unesp). Membro do Grupo de Pesquisa CNPq-Unesp "Psicologia Organizacional e do Trabalho". mario.camargo@ unesp.br
} 


\begin{abstract}
The transformation process that has been taking place in the word of work will require leaders and organizations to participate more effectively, especially in the direction of sensitizing people to understand, accept and live with these transformations. The establishment of satisfactory interactions, especially in hierarchical relationships, becomes strategic within work environments, both to optimize tasks and results and to foster the presence of a favorable work climate. These satisfactory interactions, targeted to meet current and new demands, will require leaders to have well-developed behavioral competencies, among which interpersonal competence gains a prominent role. This theoretical essay aims to discuss the importance of interpersonal competence in the repertoire of organizational leaders to meet the new demands that are presented in the workplace. It also intends to make considerations about the importance of the development of interpersonal competence in all the professionals, especially the leadership positions, presenting some possible actions in this direction. To stimulating the discussion of the presented essay, we use articles and books available in the most important specialized journals and electronic indexers, namely: Electronic Journals in Psychology (PePSIC), Scientific Electronic Library Online (SciELO), Latin American and Caribbean Center of Health Sciences Information (BIREME), LILACS, CAPES Thesis Bank, CAPES Journals and Google Scholar. Thematic relevance in relation to the object of study chosen was the main criterion for the selection of articles and book chapters considered in the study.
\end{abstract}

KEYWORDS: Leadership Development; Interpersonal Competence; Professional Social Skills; Organizational and Work Psychology.

\title{
INTRODUÇÃO
}

O mundo do trabalho contemporâneo tem sido marcado por profundas e aceleradas transformações, encontrando-se em um cenário competitivo e instável que afeta diretamente as organizações, bem como seus trabalhadores, em todos os níveis hierárquicos. Neste contexto, muito tem sido exigido de todos os profissionais que possuem importância estratégica para as organizações no tocante a buscarem o aprimoramento de suas competências, tanto na área acadêmica e gerencial, como no âmbito interpessoal.

O processo de transformação que vem ocorrendo nos contextos do trabalho, vai exigir das lideranças uma participação mais efetiva, principalmente na direção de sensibilizar pessoas para entenderem, aceitarem e conviverem com essas transformações. O papel da liderança como agente transformador e agregador de pessoas, torna-se fundamental para o enfrentamento das mudanças que já estão acontecendo e as que estão por vir no âmbito corporativo.

Assim sendo, o estabelecimento de interações satisfatórias, especialmente na relação hierárquica, torna-se estratégico dentro dos contextos de trabalho, tanto para otimizar as tarefas e resultados, como para favorecer a presença de um clima favorável de trabalho. Essas interações satisfatórias e direcionadas para atender as demandas atuais e as novas 
demandas, vai exigir das lideranças a presença de competências comportamentais bem desenvolvidas, dentre as quais, a competência interpessoal ganha papel de destaque.

Nesse atual cenário faz-se importante mudanças de paradigmas na gestão organizacional, principalmente na direção da presença de políticas e práticas de gestão que venha favorecer a melhoria da qualidade das relações interpessoais, na comunicação organizacional e, especialmente, no desenvolvimento e aprimoramento de novas competências de liderança. Portanto, ações de educação continuada ganham acentuada importância no desenvolvimento de novas habilidades para compor o perfil do novo líder.

Magaldi e Salibi Neto (2018) explicam que a revista Forbes apresentou listagem das dez qualidades que se fazem presentes num ótimo líder na atualidade. São elas: honestidade; saber delegar; comunicação; confiança; compromisso; atitude positiva; criatividade; intuição; capacidade de inspirar e de ter sintonia com as pessoas. Para os autores, embora essas qualidades sejam importantes, nada mais são do que pressupostos básicos, ou seja, são elementos fundamentais que devem estar presentes no perfil das lideranças bemsucedidas. Esses autores entendem a importância das qualidades citadas, porém indicam que é importante ir mais além, ou seja, se faz necessária a adoção de uma nova mentalidade para os líderes das transformações por que passa o mundo do trabalho, envolvendo sobretudo, o aprender a desaprender, possuir maior abertura para o novo e maior ousadia para enfrentar as novas demandas. Considerando as explicações de Magalbi e Salibi Neto (2018), pressupõe-se que as lideranças atuais e do futuro precisam reinventar-se, dando maior atenção as situações e condições que se revelam na sociedade atual. Precisam perceber e se atentar para as mudanças, quebras de paradigmas e a disrupção dos modelos vigentes, uma vez que, essas mudanças impactarão nos contextos corporativos e nas relações de negócio.

A percepção perante a necessidade de aprender cada vez mais é uma das características necessárias aos profissionais de liderança. Os novos conhecimentos devem ser apreendidos e colocados em ação, não somente porque se quer, mas porque torna-se necessário. Lins e Borges-Andrade (2014) explicam que os líderes podem aprender por meio de estratégias diversificadas, ou seja, além da participação em treinamentos gerenciais, devem adotar estratégias próprias, em respostas às demandas de seu contexto de trabalho. Importante ressaltar que a aprendizagem pressupõe mudança de comportamento, envolvendo complexa e ampla relação afetiva e cognitiva, garantindo a transformação da pessoa. Portanto, não se trata somente de aprender por processos naturais de desenvolvimento; o líder da atualidade deve considerar, a abertura e a busca por aprendizados novos, uma estratégia de gestão da própria 
carreira e da própria liderança, não necessariamente com o objetivo de tornar-se mais competitivo, mas com o objetivo de manter-se num dinamismo de atualização constante.

Aos líderes cabe o papel de se transformar e transformar as pessoas que estão ao seu redor, elevando o nível de conhecimento e aperfeiçoando comportamentos na direção de maiores e melhores resultados, tanto considerando os resultados organizacionais, como também aqueles relacionados a qualidade de vida das pessoas e a sustentabilidade da comunidade onde a organização está inserida. Para isso, deve promover e facilitar um senso de propósito coletivo e de comprometimento com o trabalho e com a sociedade como um todo. Essa complexa situação envolve o desenvolvimento e aprimoramento de novas competências, incluindo, por óbvio, a competência de liderar e de interagir assertivamente com as pessoas que lidera.

Segundo Bendassoli, Magalhães e Malvezzi (2014), a construção da liderança como competência necessária para gerenciar implica em diferentes questões que hoje estão relacionadas à influência interpessoal. Os autores destacam a questão da diversidade, ou seja, não privilegiar pessoas com as quais se identificam em detrimento a outras com as quais não se identificam por motivos étnicos, religiosos, etc. Outra questão importante diz respeito a lisura e a confiança ética nas atitudes do líder. Os autores também chamam a atenção para o tratamento das diferenças culturais por parte das lideranças, reconhecendo que a sociedade globalizada é um contexto cosmopolita. Por fim, apresentam uma questão emergente que é o conceito de liderança distribuída, ou seja, permitir-se encontrar nas equipes de trabalhos, pessoas que podem exercer a ação de liderança a partir de seu envolvimento em diferentes tarefas que são necessárias ao grupo; um movimento de mudança no comportamento de liderar que inclui a descentralização do poder e do conhecimento, bem como a habilidade de planejar e delegar tarefas, construindo interações colaborativas e solidárias de pessoas responsáveis pelo todo do fazer profissional e não, como tradicionalmente se tinha, responsabilidades por uma pequena parte do todo. Esta forma de atuação favorece uma visão mais sistêmica da organização e das relações de trabalho, contrapondo-se à uma visão fragmentada.

Revela-se portanto, a necessidade das lideranças desenvolverem habilidades para um melhor manejo e trato com as pessoas com as quais se convive profissionalmente, buscando capacitá-las, envolvê-las, motivá-las e comprometê-las, com esforços coletivos no trabalho, na busca de se atingir objetivos organizacionais e na direção da criação e manutenção de um clima favorável e salutar para a atuação profissional, ou seja, a necessidade de desenvolver e aprimorar a competência interpessoal. Nesse sentido, e como afirmam Goulart Júnior, Camargo e Moreira (2019, p. 42), “[...] além da presença de competências técnicas, precisam também 
estar preparados e em condições de lançar mão das competências humanas, ambas bem desenvolvidas".

Muniz e Bezerra (2004) argumentam que, independente do ramo de negócio, o gestor tem como papel fazer transcender o domínio da técnica e de seu conhecimento teórico, para o desenvolvimento das pessoas e de interações sociais saudáveis e produtivas. Portanto, para Amorin e Silva (2011), os responsáveis por gerenciar as pessoas tendem a reagir rapidamente às mudanças, buscando soluções capazes de estabelecer um diferencial competitivo, em que a organização é condicionada a reformular, incorporar novas tecnologias e inovar nas práticas gerenciais, valorizando o indivíduo como diferencial competitivo.

Ainda, tendo em vista o papel dos gestores nas organizações e a necessidade da presença da competência interpessoal bem desenvolvida, Martins, Carvalho e Carvalho (2017), afirmam que o gestor além de planejar, organizar, liderar e controlar, também tem que saber administrar conflitos, desenvolver o papel motivacional para sua equipe, criando um ambiente propício para que sejam realizados os objetivos da organização.

O presente ensaio teórico tem como objetivo discorrer sobre a importância da presença da competência interpessoal no repertório das lideranças organizacionais visando atender as novas demandas que se apresentam no ambiente corporativo. Pretende também tecer considerações acerca da importância do desenvolvimento da competência interpessoal em todos os profissionais de um ambiente corporativo, com destaque para os cargos de liderança, apresentando algumas possíveis ações nessa direção. Para tanto, utilizamos enquanto método de busca por publicações e fundamentação teórica de nossa discussão, artigos e livros presentes em periódicos especializados e indexadores eletrônicos como Periódicos Eletrônicos em Psicologia (PePSIC), Scientific Electronic Library Online (SciELO), Centro LatinoAmericano e do Caribe de Informação em Ciências da Saúde (BIREME), LILACS, Banco de Teses da CAPES, Periódicos CAPES e Google Scholar. Consideramos, ao final das buscas empreendidas, somente os artigos científicos e livros cujos títulos e escopo faziam referência ao tema "competência interpessoal" no contexto da atuação de profissionais, tanto em cargos de liderança e gestão como em âmbito geral das organizações.

\section{COMPETENCIA INTERPESSOAL: BREVES CONSIDERAÇÕES}

Encontram-se na literatura diferentes definições e concepções teóricas para competência, porém Brandão e Borges-Andrade (2007), assim como Carboni, Brandão, Leite e Vilhena (2009) apresentam uma abordagem que parece integrar as demais, ou seja, a definição de competência como um conjunto de atributos pessoais, relacionados ao 
conhecimento (saberes acumulados), habilidades (saber fazer) e atitudes (valores) (CHA) que são necessários para o bom desenvolvimento do exercício laboral (profissional e organizacional) e as realizações exitosas.

Entre as inúmeras competências que são exigidas de um gestor na atualidade, destaca-se a competência interpessoal. A competência interpessoal é necessária ao profissional de liderança na atualidade, visto que o habilita a atuar de forma eficaz no âmbito das relações interpessoais, diante das mais diversas situações (MUNARI; BEZERRA, 2004). Para os autores, os primeiros estudos sobre a competência interpessoal datam do início da década de 1960, quando se observava que a presença dessa competência melhorava o desempenho grupal na execução de tarefas, bem como, na capacidade de produção, de articulação e na satisfação dos sujeitos no desenvolvimento do trabalho coletivo.

Alguns autores buscaram discutir a importância da competência interpessoal e para melhor compreensão dos principais construtos relacionados a essa competência, Muniz, Rell e Ferreira (2017), resumiram os estudos mais relevantes que são apresentados na Tabela 1.

Tabela 1 - Definição de Competência de Relacionamento Interpessoal

\begin{tabular}{|c|c|c|}
\hline AUTOR & TÍTULO & DEFINIÇÃ̃O \\
\hline Moscovici, F. (1981) & $\begin{array}{l}\text { Competência interpessoal no } \\
\text { desenvolvimento de gerentes }\end{array}$ & $\begin{array}{l}\text { Habilidade de lidar eficazmente com } \\
\text { relações interpessoais, de lidar com outras } \\
\text { pessoas de forma adequada às necessidades } \\
\text { de cada um e às exigências da situação. }\end{array}$ \\
\hline $\begin{array}{l}\text { Gomes, A. F.; Santana, W. } \\
\text { G. P. (2004) }\end{array}$ & $\begin{array}{l}\text { As habilidades } \mathrm{de} \\
\text { relacionamento interpessoal de } \\
\text { mulheres que trabalham por } \\
\text { conta própria: o caso de Vitória } \\
\text { da Conquista - BA }\end{array}$ & $\begin{array}{l}\text { O Relacionamento interpessoal é a } \\
\text { capacidade de buscar convívio harmonioso } \\
\text { em seu ambiente de trabalho e de saber } \\
\text { relacionar-se com clientes e fornecedores, } \\
\text { possibilitando um trabalho através do qual a } \\
\text { maioria das pessoas sinta prazer e disposição } \\
\text { de "dar o melhor de si". }\end{array}$ \\
\hline Valle, P. B. (2006) & $\begin{array}{llr}\text { Inteligência } & \text { emocional no } \\
\text { trabalho: } & \text { um } \quad \text { estudo } \\
\text { exploratório. } & & \end{array}$ & $\begin{array}{l}\text { Habilidade de mediar eficazmente as } \\
\text { necessidades relacionais e situacionais; isto } \\
\text { é, levar em conta as necessidades pessoais } \\
\text { (ou interpessoais) de forma que estas } \\
\text { cumpram com as exigências do contexto em } \\
\text { que estão inseridas. }\end{array}$ \\
\hline $\begin{array}{l}\text { Paiva, F. G.; Fernandes, N. } \\
\text { C. M. (2012) }\end{array}$ & $\begin{array}{l}\text { A contribuição da competência } \\
\text { relacional do empreendedor para } \\
\text { aperfeiçoar a qualidade de } \\
\text { relacionamento entre empresas } \\
\text { de base tecnológica }\end{array}$ & $\begin{array}{l}\text { A "habilidade interpessoal" está vinculada à } \\
\text { capacidade de se relacionar e auxilia no } \\
\text { estabelecimento de relacionamentos de } \\
\text { qualidade. }\end{array}$ \\
\hline $\begin{array}{l}\text { Santos, M. G.; Brito, Jesus, } \\
\text { K. C.; Souza, J. C. S.; } \\
\text { Castro, M. A. R. (2014) }\end{array}$ & $\begin{array}{l}\text { Modalidades de aprendizagem } \\
\text { organizacional nos programas } \\
\text { trainees: Desenvolvendo a } \\
\text { habilidade interpessoal }\end{array}$ & $\begin{array}{l}\text { As habilidades interpessoais se referem às } \\
\text { habilidades de relacionamento do gestor com } \\
\text { sua equipe de subordinados, ou seja, as } \\
\text { pessoas da organização que fazem parte da } \\
\text { hierarquia organizacional em posições mais } \\
\text { baixas do que as do gestor. }\end{array}$ \\
\hline
\end{tabular}

Fonte: Muniz, Rell e Ferreira (2017). 
De maneira geral, os autores relacionados por Muniz, Rell e Ferreira (2017), postulam de modo geral que a competência interpessoal está relacionada com a capacidade de lidar com pessoas de maneira eficaz, estabelecendo relacionamentos de qualidade no trabalho. Gomes e Santana (2004) estendem essa habilidade para outras pessoas envolvidas com o negócio da organização, ou seja, no trato com clientes e fornecedores, enquanto que para Santos et al. (2014), a habilidade interpessoal do gestor consiste em se relacionar adequadamente com sua equipe, na hierarquia organizacional. Ademais, Moscovici (1981) e Vale (2006), enfatizam que essa habilidade está relacionada às exigências do meio, enquanto Gomes e Santana (2004), dão ênfase ao convívio harmonioso no ambiente de trabalho.

Carlos (2011) explica que o aprimoramento da habilidade de relacionamento interpessoal pode ocorrer de maneira informal no convívio diário, por meio da inteligência emocional e capacidade de resiliência. Para Moscovici (2013), quanto mais detalhada for a visão que o indivíduo possui de si, melhor será sua visão interpessoal e sua habilidade em lidar com situações interpessoais, envolvendo flexibilidade perceptiva e comportamental para ver os vários ângulos existentes de uma mesma situação e atuar de forma diferenciada. Ainda segundo a autora, diversas ferramentas fundamentais para a gestão da organização somente apresentarão resultados satisfatórios se o gestor e seus liderados possuírem suas competências interpessoais bem desenvolvidas. Conforme apontam Pagliaci, Alves e Camargo (2019), o desenvolvimento e manutenção de boas relações interpessoais no trabalho, dependem do investimento em programas de treinamento de algumas habilidades sociais esperadas como repertório de um líder, tais como: saber se impor e ser firme sem que use de autoritarismo, ou seja, ser assertivo, ter comportamento empático e disponibilidade de abertura para a escuta das demandas trazidas pelos trabalhadores no cotidiano de trabalho.

Munari e Bezerra (2004), explicam que, potencializar a competência interpessoal dos profissionais, sejam gestores ou não, pode agregar ótimos benefícios à performance da equipe, e consequentemente, ao sucesso da organização. Os autores argumentam que:

o profissional que desenvolve sua competência interpessoal, possui maior capacidade em lidar com as situações de conflito, em potencializar talentos e gerir trabalho em um clima de confiança e satisfação. Assim, ele deixa de olhar apenas para si, podendo tornar-se capaz de compreender a complexidade das relações entre seres humanos (p.485).

A percepção acurada pelo desenvolvimento da competência interpessoal permite que o sujeito desempenhe melhor o seu trabalho, tanto na dimensão técnica requerida pela natureza da atividade, quanto na de ser capaz de se posicionar de forma habilidosa nas redes 
de relações interpessoais, internas e externas à organização. Ademais, a competência interpessoal é revelada na relação indivíduo-indivíduo e nas relações indivíduo-grupo, englobando assim atitudes individuais e coletivas que jamais são indissociáveis (RODRIGUES; IMAI; FERREIRA, 2001).

Atualmente encontramos uma derivação do conceito de competência interpessoal denominada de competência relacional que significa articular-se de modo singular no adequado manejo e interação entre três componentes indissociáveis na prática grupal e da vida institucional: autoridade, liderança e exercício do poder (OSÓRIO, 2003). Nessa perspectiva, é mister a qualquer profissional da atualidade, que desenvolva a sua competência para melhor lidar com as relações, já que muitos atuam como gestores de serviços e equipes, dentro de um sistema extremamente complexo, que envolve diversos profissionais atuando em um mesmo ambiente (MUNARI; BEZERRA, 2004).

\section{O DESENVOLVIMENTO DA COMPETÊNCIA INTERPESSOAL EM GESTORES: PROPOSTA PARA INTERVENÇÃO}

Moscovici (2002) destaca que a competência interpessoal é de grande importância a todos os profissionais, não só para aqueles que lidam diretamente com o público ou que atuam em cargos estratégicos, como as lideranças por exemplo. Segundo Crispim e Fraganani (2010), a presença da competência interpessoal vai requerer do gestor o desenvolvimento de algumas habilidades que o possibilitem lidar com as situações relacionais do ambiente organizacional. No tocante ao desenvolvimento dessa competência no repertório comportamental dos gestores, Moscovici (2002) explica que mesmo que algumas pessoas tenham mais facilidade para se relacionar que outras, a competência interpessoal não é algo inato ao indivíduo e, para tal, é necessário que os indivíduos passem por um processo de treinamento e desenvolvimento para aquisição das habilidades relacionais.

Entre as habilidades necessárias para o desenvolvimento da competência interpessoal, Crispim e Fragnani (2010) destacam algumas como as habilidades de liderança, de comunicação, capacidade de motivar pessoas, capacidade de negociação e de resolução de conflitos. No que diz respeito às habilidades de liderança, Hunter (2006) destaca que liderar consiste em conquistar pessoas, envolvê-las para que coloquem sua mente, criatividade e excelência para alcançar um objetivo, fazendo com que elas se comprometam ao máximo nessa missão. Botelho e Krom (2006), destacam que o líder não só coordena as atividades, mas também têm como papel a coordenação das pessoas. Segundo os autores, este profissional é o principal responsável pelos resultados obtidos por meio da influência que ele exerce sobre os 
demais. Pereira, Schneider e Silva Júnior (2016), destacam a importância de um líder saber alinhar as exigências da situação à gestão eficaz das pessoas envolvidas nos projetos de trabalho. Segundo estes autores, no caso do gerenciamento de projetos, o líder tem como papel delegar as atribuições de forma clara e saber cobrá-las, para tanto, também são de suma importância as habilidades de comunicação.

Reportando-se as habilidades de comunicação, Soares (2005) destaca que os líderes/gerentes que se comunicam eficazmente, as utilizam para conceder poder às pessoas, reconhecer e reforçar a realização das tarefas e ainda incentivar o desempenho da equipe. Crispim e Fragnani (2010) argumentam que, atuando como o principal fator de informação, a comunicação eficaz estabelece as metas específicas requeridas para o alcance dos objetivos organizacionais e são assim compreendidas por todos; a boa comunicação também favorece os processos de negociação e tomadas de decisões, avaliando estrategicamente as melhores alternativas de ações. Para os autores, a habilidade de se comunicar confere ao gestor estilos diferentes de abordagem nas interações, tomando por base as diferenças individuais, tornandoo mais assertivo. Isso impacta no clima organizacional positivamente e, consequentemente, nos resultados do trabalho.

A partir do momento em que as diferenças são tratadas abertamente, a comunicação passa a fluir adequadamente dando espaço para as pessoas se ouvirem e falarem abertamente sobre o que sentem e pensam, possibilitando o dar e receber de feedback assertivamente. Crispim e Fragnani (2010) explicam que quando esse processo não acontece e as diferenças são negadas, a comunicação torna-se falha, insuficiente, com bloqueios e distorções, desencadeando tensões e conflitos, desintegração de esforços e deterioração do desempenho grupal, o que afeta direta e negativamente a produtividade e as relações.

Ainda no tocante a comunicação, as práticas de feedback constroem um processo que possibilita conversas entre gestores e trabalhadores de modo que ambos estabeleçam uma sintonia em torno dos alvos e objetivos da organização (BARROS; MATOS, 2015). Ferreira (2013) afirma que o feedback é extremamente importante na gestão de desempenho nas organizações, pois, através dele, é possível proporcionar o desenvolvimento contínuo do trabalhador em sua rotina de trabalho e, por isso, é considerado um processo de ajuda e estímulo para mudanças de comportamento nas organizações. Existem diferentes formas de realizar o feedback, ou seja, ele pode ser expresso pela comunicação verbal, ou não verbal, pela comunicação escrita, por meios digitais, etc., porém a qualidade desse feedback tem relação direta com o nível de desenvolvimento da competência interpessoal de quem o realiza. 
Os líderes que desejam aprimorar sua comunicação junto aos liderados precisam compreender a devida importância do feedback e devem buscar desenvolvimento nessas práticas, contribuindo positivamente para esse momento (BARROS; MATOS, 2015). Um líder de destaque utiliza o feedback como ferramenta e busca desenvolver suas habilidades para aprimorar o desenvolvimento dos seus trabalhadores. A habilidade do gestor na realização do feedback é fundamental para que esse atinja seu objetivo.

Turci (2013) menciona que a prática de realizar o feedback também é importante pela construção de valores e pelo aumento do sentimento de satisfação de quem recebe o feedback. Os sentimentos de satisfação podem ser percebidos em vários aspectos, tais como o aumento da autoconfiança, da valorização, no crescimento profissional, no fortalecimento da relação entre trabalhador e gestor, etc.

Retratando sobe a habilidade de motivar pessoas, é possível afirmar que o comportamento humano no trabalho resulta do conjunto de vários aspectos motivacionais, dando espaço para a humanização nas organizações, nas quais os trabalhadores podem exercer suas atividades sentindo-se úteis e importantes (CRISPIM; FRAGNANI, 2010). A motivação tem sido apontada como um dos maiores desafios e preocupações das organizações modernas, isto porque se sabe que trabalhadores motivados geram um diferencial, em termos de desempenho, para as organizações buscarem os resultados desejados. Martins, Carvalho e Carvalho (2017) explicam que a motivação pode ser entendida como uma razão que leva as pessoas à uma ação ou comportamento. Os autores ressaltam também a necessidade dos gestores se atentarem para o clima organizacional, proporcionando um ambiente de trabalho confortável e seguro, propondo momentos de interação e socialização entre os trabalhadores. Devem se atentar também para as práticas de gestão de pessoas, como por exemplo, planos de carreira, remuneração adequada e justa, benefícios sociais, a oferta de boas condições físicas e psicológicas do trabalho, pois essas também são elementos importantes que impactarão na motivação dos trabalhadores, um fenômeno entendido como multifatorial.

Para Martinelli e Almeida (2006), considerando a habilidade de negociação, explicam que essa habilidade caracteriza-se por um processo de comunicação que visa influenciar o comportamento, a fim de se chegar a uma decisão conjunta. Argumentam que a habilidade de negociação pode ser considerada como um elemento fundamental na atuação gerencial já que, é através dela que é possível chegar a consensos, elaborar estratégias, adquirir subsídios e incentivos para sua equipe de trabalho. Para Crispim e Fragnani (2010) quanto maior o número de pessoas envolvidas no processo de negociação, maior a probabilidade de impasses, já que há um maior número de pontos de vista envolvidos. Assim, a familiaridade 
do gerente com os conceitos e processos básicos de negociação assume cada vez mais importância, visto que, neste processo estão envolvidos assuntos diários da organização, tais como: salários, objetivos da tarefa, atribuições, local de trabalho, privilégios, entre outros.

Para Chrispino (2007), o conflito é parte integrante da vida e da atividade social das pessoas, originando-se, em muitas vezes, da diferença de interesses, de desejos e de aspirações. Para o autor pode não existir a noção estrita de erro e de acerto, mas de posições que são defendidas frente a outras, diferentes.

Os conflitos são construtivos quando: melhoram a qualidade das decisões, estimulam a criatividade e inovação; encorajam interesses e a curiosidade entre membros de equipes; fornecem meios pelos quais os problemas podem ser manifestados, diminuindo tensões; e fomentam um ambiente de autoavaliação e mudança (BACAL, 2004). Tendências contemporâneas visualizam o conflito como um fenômeno inevitável e que está presente nas organizações. Porém, acredita-se que o mesmo deva ser gerenciado adequadamente para promover mudanças no ambiente de trabalho. O conflito, quando não é gerenciado de maneira adequada pode desperdiçar tempo e energia, desviando as pessoas do caminho para alcançar metas importantes (FERREIRA, 2010).

A tarefa de mediar de conflitos nas relações de trabalho requer por parte do lídergestor, refinada habilidade no trato com as pessoas, posto que, independente da característica dos conflitos, estarão envolvidas uma ou mais pessoas do contexto de trabalho. A habilidade nas relações favorece não somente a busca pela melhor solução para o conflito mediado, mas, principalmente, que os envolvidos não apresentem mágoas ou ressentimentos que impactarão na sua satisfação com o trabalho e no relacionamento interpessoal com colegas e lideranças.

A potencialização do desenvolvimento da competência interpessoal nos trabalhadores, especialmente aqueles em cargo de gestão, pode gerar resultados satisfatórios de melhores desempenhos individuais como também das equipes e, consequentemente, melhores resultados organizacionais como um todo. Porém esse desenvolvimento vai demandar ações estratégicas e investimentos das organizações na direção de iniciativas de formação e capacitação, considerando que essa competência, como muitas outras, podem ser ensinadas. Vai incidir também em suporte organizacional para que o profissional possa, por meio de iniciativas pessoais, buscar o autodesenvolvimento na direção de aprimorar e desenvolver as competências necessárias ao bom desempenho profissional, alinhado com as novas exigências do trabalho.

Brandão (2005), afirma que é necessário apoiar as iniciativas de desenvolvimento profissional, através da criação de um ambiente que seja propício à aprendizagem. Portanto, 
faz-se necessário que as organizações invistam no desenvolvimento da competência interpessoal de seus gestores e demais trabalhadores, com capacitações e treinamentos, estabelecendo assim uma rede de aprendizagem dentro da organização (MARTINS, CARVALHO; CARVALHO, 2017).

Moscardino e Klein (2015), inferem que o desenvolvimento de líderes e gestores representa uma demanda necessária e uma das mais importantes metas para organizações que buscam expansão. Os autores indicam uma evolução do tradicional Treinamento e Desenvolvimento (T\&D), para a chamada Educação Corporativa (EC), que pode ser definida como um conjunto de estratégias educacionais contínuas que a organização deve promover, fundamentada em metas futuras, nas estratégias e na cultura organizacional, com o objetivo de desenvolver competências críticas para o negócio.

Desta maneira, a capacitação e desenvolvimento da competência interpessoal por meio da Educação Corporativa, pode-se utilizar de variadas estratégias, como exemplo: (a) aulas expositivas - através de uma atividade educacional formal (PACHECO et al., 2009); (b) debates - tipo de estratégia que permite a discussão e a reflexão coletiva (ANTONELLO; GODOY, 2011); (c) aprendizagem baseada em problemas - que envolve a resolução de problemas identificados no contexto de trabalho (MILHEM et al., 2014); (d) estudos de caso - análise de dados e proposta de soluções aos problemas apresentados (PACHECO et al., 2009); (e) dramatização - representação de uma determinada situação ou fato, baseada em situações reais do cotidiano (PACHECO et al., 2009); (f) workshop ou oficinas de trabalho - envolve sessões de aprendizagem prática, por meio de ações (ANTONELLO; GODOY, 2011); (g) jogos - atividades lúdicas que sejam colaborativas e envolvam atividades com objetivos claros a serem atingidos (MILHEM et al., 2014); (h) coaching - acompanhamento do indivíduo por um profissional capacitado e que incentive o indivíduo a pensar em suas ações e seu desenvolvimento (PACHECO et al., 2009); e (i) mentoring - um indivíduo mais experiente orienta outro para o aprimoramento de suas competências (MILHEM et al., 2014).

O Treinamento de Habilidades Sociais Profissionais (THSP) também se configura como importante estratégia para o desenvolvimento de competências relacionais. Segundo Rodrigues, Araújo, Ribeiro e Rubio (2015) os estudos em habilidades sociais profissionais têm sido relevantes por contribuírem com o trabalhador e, consequentemente, com a organização, elevando a eficácia dos indivíduos e aumentando os resultados organizacionais. A literatura nacional sobre habilidades sociais nos contextos de trabalho, segundo Silva e Goulart Júnior (2019), ainda é escassa, limitando-se a apresentação de resultados a partir de instrumentos aplicados em profissionais para a identificação dessas habilidades. Segundo os autores é menor 
ainda a frequência de publicações apresentando procedimentos e resultados de treinamentos de habilidades sociais no trabalho, indicando que este é um importante campo de estudo e desenvolvimento de práticas a ser explorado.

Com relação às técnicas para se treinar Habilidades Sociais, Del Prette e Del Prette (2012) afirmam que é possível fazer uso de reestruturação cognitiva ou técnicas comportamentais, com ensaio comportamental, reforçamento, modelagem, modelação, feedback, relaxamento, tarefas de casa e dessensibilização sistemática. A técnica de ensaio comportamental vem sendo muito utilizada por possibilitar o desenvolvimento de novos repertórios comportamentais, garantir maior controle sobre o próprio desempenho e possibilitar o desenvolvimento de melhor observação das contingências envolvidas na interação. Para a utilização da técnica comportamental, o uso de modelagem, feedback, modelação e tarefas de casa são bastante importantes, sendo a tarefa de casa um dos maiores aliados para aperfeiçoar os novos repertórios aprendidos e treinados, bem como buscar a generalização de respostas e permitir a verificação de como o ambiente natural reage ao novo repertório do indivíduo (DEL PRETTE; DEL PRETTE, 2012).

Boas et al., (2005, citado por Silveira, Goulart Junior, Cardoso e Bolsoni-Silva, 2016), treinaram habilidades sociais em quatro participantes gestores fazendo uso da perspectiva analítico-comportamental, oferecendo 22 sessões semanais com duas horas de duração à luz dos temas: assertividade, comunicação, dar e receber feedback, direitos humanos, expressar sentimentos negativos, lidar com críticas e autoconhecimento, elogiar e agradecer elogios, de modo que, ao final do treinamento, os participantes relataram facilidade em emitir grande parte dos repertórios treinados, demonstrando assim a eficácia da intervenção.

Silveira, Goulart Junior, Cardoso e Bolsoni-Silva (2016), elaboraram um modelo de treinamento de Habilidades Sociais Profissionais para lideranças. Os temas trabalhados no treinamento proposto foram distribuídos em 8 categorias a saber: (a) relacionamento interpessoal; (b) cumprimento de metas e objetivos do trabalho; (c) respeito aos direitos e diferenças individuais; (d) comunicação organizacional; (e) resoluções de conflitos no trabalho/autocontrole; (f) gestão do desempenho humano no trabalho; (g) gestão de pessoas e (h) lidar com o estresse e os estressores ocupacionais. O treinamento proposto contempla 20 sessões, com duração de três a quatro horas cada. As sessões deverão ser realizadas após diagnóstico inicial, a fim de levantar os principais déficits e reservas do grupo de gestores de modo a observar os temas mais relevantes para o mesmo, a serem discutidos com maior ênfase e aprofundamento durante o processo de intervenção. 
Evidencia-se assim, que o Treinamento em Habilidades Sociais Profissionais pode ser importante intervenção na direção do desenvolvimento e aprimoramento de competências para diferentes profissionais de uma organização, destacando aqueles de nível gerencial ou demais lideranças, a quem, dadas as responsabilidades e constante necessidade de estabelecer contato e relações com outras pessoas no contexto da estrutura organizacional, especialmente se beneficiariam com o desenvolvimento de competências interpessoais.

\section{CONSIDERAÇÕES FINAIS}

A gestão de competências como prática corrente no gerenciamento cotidiano e estratégico das pessoas nas organizações, abre inúmeros caminhos para tornar os profissionais e gestores melhor preparados para os desafios enfrentados diariamente nas organizações. Partese do pressuposto que o desenvolvimento de competências caracteriza-se enquanto processo contínuo, planejado estrategicamente. Esse processo pode se dar de maneira formal e informal, sempre integrado às necessidades e objetivos organizacionais, olhando para a contemporaneidade, mas, sobretudo, para as exigências e necessidades futuras das organizações de trabalho. $\mathrm{O}$ aprimoramento contínuo de conhecimentos, habilidades e atitudes, representam ações das mais simples às mais complexas, na direção de um quadro funcional mais capacitado e preparado para assimilar e atuar com maior competência sobre as demandas do trabalho, melhorando o desempenho individual, coletivo e organizacional.

Pode-se considerar que o desenvolvimento da competência interpessoal é imprescindível para uma atuação mais elevada dos profissionais de responsabilidade gerencial, principalmente no que diz respeito à forma como esses interagem com seus pares e liderados. Assim, um gestor que possui sua competência interpessoal bem desenvolvida, pode gerir a sua equipe para obtenção de melhores resultados, não só organizacionais, como também pessoais. Devemos considerar como um dos ganhos, ou efeito colateral positivo, de uma liderança qualificada do ponto de vista da competência interpessoal reside justamente no modo como este administrará suas relações interpessoais no contexto organizacional, representando um novo paradigma de liderança, em especial, mais humanizado.

Assim, podemos considerar que a presença da competência interpessoal em gestores organizacionais, além de otimizarem resultados, também favorecem um clima saudável de trabalho, na medida em que as interações e os relacionamentos interpessoais tornam-se mais assertivos, honestos e justos. Esse clima favorável contribui sobremaneira para a saúde física, mas especialmente, para a promoção e preservação da saúde mental dos trabalhadores, e, não obstante, participa da prevenção de riscos psicossociais que poderiam 
contribuir para o desenvolvimento, ou agravamento, dos chamados transtornos mentais e do comportamento relacionados ao trabalho (BRASIL, 2001; BENITES; CAMARGO; GOULART JÚNIOR; CAMARGO, 2013). Isso porque onde os conflitos de trabalho são melhores conduzidos e administrados, a relação de confiança mútua poderá estar mais presente.

Obviamente que só a presença da competência interpessoal bem desenvolvida nos gestores de forma isolada não será suficiente para melhores resultados organizacionais em todos os seus níveis. Outras políticas, processos e práticas de gestão de pessoas precisam estar alinhadas às necessidades organizacionais e dos trabalhadores. No entanto, é inegável que o gestor melhor preparado, consegue, além de estabelecer melhores relacionamentos, perceber com mais precisão os aspectos disfuncionais do trabalho, fazendo diagnósticos mais precisos sobre o que precisa ser mudado e alcançado na direção de um ambiente corporativo mais produtivo e favorecedor de bem estar e saúde para seus componentes. Sendo assim, podem alavancar ações, cobrando de quem de direito, iniciativas e mudanças nessa direção.

O desenvolvimento e o aprimoramento das competências necessárias à boa condução de uma organização de trabalho não é tarefa simples e fácil. Requer equipes competentes atuando em gestão de pessoas, que possam articular ações estratégicas em suas práticas, que vão, desde renovadas formas de realizar recrutamento e seleção de pessoas, até ações acentuadas de educação para o trabalho e gestão do desempenho humano.

No tocante ao desenvolvimento e aprimoramento da competência interpessoal em gestores, tema central desse texto, a questão torna-se mais complexa, sobretudo considerando que, nos processos formativos de muitos profissionais, se privilegia, quase que exclusivamente, a formação técnica em detrimento a uma formação mais dirigida às relações interpessoais. Em grande parte dos cursos de formação em áreas de exatas, por exemplo, não existe na grade curricular disciplinas que capacitem o futuro profissional para um desempenho mais positivo nas relações com pessoas, constituindo-se assim, ao nosso olhar, falha significativa, sobretudo considerando as novas dinâmicas e exigências do trabalho.

No entanto, o desenvolvimento de competências é um processo que se aprende e se ensina, portanto, passível de ser implementado em qualquer organização do trabalho, desde que haja investimentos adequados para tal. As novas exigências do trabalho, sobretudo as de futuro próximo, vão explicitar a necessidade de constante desenvolvimento e aprimoramento de algumas competências consolidadas para o trabalho, mas também, novas competências que emergirão dependendo do negócio da organização. Assim sendo, todas as organizações que forem na direção de melhores resultados terão que, de um jeito ou de outro, investir nessa questão. 


\section{REFERÊNCIAS BIBLIOGRÁFICAS}

ANTONELlO, C. S.; GODOY, A. S. Aprendizagem Organizacional no Brasil. Porto Alegre: Bookman, 2011.

BACAL, R. Organizational Conflict - The good, the bad, and the ugly. In: The Journal for Quality \& Participation. EUA, 2004.

BENDASSOLI, P. F.; MAGALHÂES, M. O.; MALVEZZI, S. Liderança nas Organizações. In: ZANELLI, J. C.; BORGES-ANDRADE, J. E.; BASTOS, A. V. B. (Orgs.). Psicologia, Organizações e Trabalho no Brasil. 2. ed. Porto Alegre: Artmed, 2014. p. 413-449.

BENITES, A. C.; CAMARGO, I. S.; GOULART JÚNIOR, E.; CAMARGO, M. L. Relação entre transtorno do ciclo vigília-sono e trabalho noturno: desafios à segurança e saúde do trabalhador. R. Laborativa. v. 2, n. 2, p. 86-107, out./2013. Disponível em: <http://ojs.unesp.br/index. php/rlaborativa>. Acesso em: 28 set. 2019.

BARROS, D. M. L.; MATOS, N. S. A importância da comunicação organizacional interna e dos feedbacks gerenciais. Revista de Administração, Universidade Regional Integrada do Alto Uruguai e das Missões, v. 13, n. 23, 2015. Disponível em: <http://revistas.fw.uri.br/index.php/revistadeadm/article/view/1553/1961 >. Acesso em: 28 set. 2019.

BOAS, A. C. V. B. V.; SILVEIRA, F. F.; BOLSONI-SILVA, A. T. Descrição e efeitos de um procedimento de intervenção em grupo com universitários: um estudo piloto. Revista Interação em Psicologia, v. 9, n.2, p. 323-332, 2005. http://dx.doi.org/10.5380/psi.v9i2.4784.

BOTELHO, J. C.; KROM, V. Os estilos de liderança nas organizações. XIV INIC - Encontro Latino Americano de Iniciação Científica. 2006. Disponível em: <http://www.inicepg.univap.br/cd/INIC_2010/anais/arquivos/0003_0494_01.pdf>. Acesso em: 28 set. 2019.

BRANDÃO, H. P.; BAHRY, C. P. Gestão por competências: métodos e técnicas para mapeamento de competências. Revista do Serviço Público, Brasília, v. 56, n. 2, p. 179-194. 2005.

Disponível

em: <https://repositorio.enap.gov.br/bitstream/1/1504/1/2005\%20Vol.56\%2Cn.2\%20Brand\%C3 \%A3o\%20e\%20Bahry.pdf $>$. Acesso em: 28 set. 2019.

BRANDÃO, H. P.; BORGES-ANDRADE, J. E. Causas e efeito da expressão de competência no trabalho: para entender melhor a noção de competência. Revista Administração Mackenzie, v. 8, n. 3, p. 32-49, 2007. Disponível em: <http://editorarevistas.mackenzie.br/index.php/RAM/article/view/136>. Acesso em: 28 set. 2019.

BRASIL. Ministério da Saúde. Doenças relacionadas ao trabalho: manual de procedimentos para os serviços de saúde. Brasília, DF: Ministério da Saúde, 2001.

CARBONI, P. P.; BRANDÃO, H. P.; LEITE, J. B.; VILHENA, R. M. Gestão por Competência e gestão do conhecimento. Rio de Janeiro: Fundação Getúlio Vargas, 2009. 
CARLOS, J. Definições de Relacionamentos Interpessoais. Revista Intellectus, a. VIII, n. 20, 2011. Disponível em: <http://www.revistaintellectus.com.br/ArtigosUpload/20.212.pdf>. Acesso em: 28 set. 2019.

CRISPIM, A. L.; FRAGNANI, E. C. S. F. A importância da competência interpessoal para a atuação do gerente no contexto organizacional. UNESC, 2010. Disponível em: <https://www.researchgate.net/publication/265917161_A_Importancia_da_Competencia_Int erpessoal_para_a_Atuacao_do_Gerente_no_Contexto_Organizacional >. Acesso em: 28 set. 2019.

DEL PRETTE, Z. A.; DEL PRETTE, A. Técnicas de Treinamento de Habilidades Sociais. In: DEL PRETTE, Z. A.; DEL PRETTE, A. (Orgs.). Psicologia das Habilidades Sociais: Terapia, educação e trabalho. 9. ed. Petrópolis: Vozes, 2012. p. 116-143.

FERREIRA, D. S. A importância do feedback no processo de avaliação de desempenho nas organizações da zona da mata mineira. Revista Científica Semana Acadêmica. Fortaleza, a. MMXII, n. 15, 2013. Disponível em: <https://semanaacademica.org.br/artigo/importancia-dofeedback-no-processo-de-avaliacao-de-desempenho-realizado-nas-organizacoes-da $>$. Acesso em: 28 set. 2019.

FERREIRA, H. M. G. Conflito Interpessoal em equipes de trabalho: O papel do líder como gerente das emoções do grupo. Cadernos UniFOA, Volta Redonda, v. 5, n. 13, p 67-75, 2010. Disponível em: <http://revistas.unifoa.edu.br/index.php/cadernos/article/view/1019>. Acesso em: 28 set. 2019.

GOMES, A. F.; SANTANA, W. G. P. As Habilidades de Relacionamento Interpessoal de Mulheres que Trabalham por Conta Própria: O Caso de Vitória da Conquista-Ba. VII SemeAd, ago. 2004.

GOULART JÚNIOR, E.; CAMARGO, M. L.; MOREIRA, M. C. Habilidades Sociais Profissionais: produção científica nacional e relevância do tema para a saúde dos trabalhadores. Revista de Psicologia, v. 10, n. 2, p. 41-50, 1 jul. 2019. Disponível em: <http://www.periodicos.ufc.br/psicologiaufc/article/view/39967>. Acesso em: 28 set. 2019.

HUNTER, J. C. O monge e o executivo. Rio de Janeiro: Sextante, 2006.

LINS, M. P. B. E.; BORGES-ANDRADE, J. E. Expressão de competências de liderança e aprendizagem no trabalho. Estud. psicol. (Natal), Natal, v. 19, n. 3, p. 159-168, set. 2014. Disponível em: <http://www.scielo.br/scielo.php?script=sci_arttext\&pid=S1413294X2014000300001\&lng=en\&nrm=iso.$\quad$ Acesso $\quad$ em: 24 set. 2019. http://dx.doi.org/10.1590/S1413-294X2014000300001.

MAGALDI, S; SALIBI NETO, J. Gestão do Amanhã: tudo o que você precisa saber sobre gestão, inovação e liderança para vencer a $4^{a}$ Revolução Industrial. São Paulo: Gente, 2018.

MARTINELLI, D. P.; ALMEIDA, A. P. Negociação e solução de conflitos: do impasse ao ganha-ganha através do melhor estilo. São Paulo: Atlas, 2006.

MARTINS, E. M.; CARVALHO, N. M. R.; CARVALHO, V. D. R. O papel do gestor e os impactos do clima organizacional para a qualidade de vida dentro das organizações. Revista 
Multidebates, v. 1, n.2, 2017. Disponível em: <revista.faculdadeitop.edu.br > index.php > revista > article > download >. Acesso em: 28 set. 2019.

MOSCOVICI, F. Competência interpessoal no desenvolvimento de gerentes. Rev. adm. empres., São Paulo, v. 21, n. 2, p. 17-25, jun. 1981. Disponível em: <http://www.scielo.br/scielo.php?script=sci_arttext\&pid=S003475901981000200002\&lng=en\&nrm=iso>. Acesso $\quad$ em: 28 set. 2019. http://dx.doi.org/10.1590/S0034-75901981000200002.

MOSCOVICI, F. Desenvolvimento interpessoal: treinamento em grupo. Rio de Janeiro: José Olympio, 2002.

MOSCOVICI, F. Desenvolvimento interpessoal: Treinamento em grupo. 22. ed. Rio de Janeiro: José Olympio, 2013.

MUNARI, D. B.; BEZERRA, A. L. Q. Inclusão da competência interpessoal na formação do enfermeiro como gestor. Revista Brasileira de Enfermagem, Brasília, v. 57, n. 4, p. 484-486. 2004. Disponível em: <http://www.scielo.br/scielo.php?pid=S0034$71672004000400020 \&$ script=sci_abstract\&tlng=pt $>$. Acesso em: 28 set. 2019.

MUNIZ, A. S.; RELL, M. L.; FERREIRA, E. S. Gestão de Pessoas em Projetos: A Importância da Competência Interpessoal. VI Singep - Simpósio Internacional de Gestão de Projetos, Inovação e $\quad$ Sustentabilidade. $2017 . \quad$ Disponível em: <https://singep.org.br/6singep/resultado/390.pdf>. Acesso em: 28 set. 2019.

OSÓRIO, L. C. Psicologia Grupal: uma nova disciplina para o advento de uma era. Porto Alegre: Artes Médicas, 2003.

PACHECO, L.; SCOFANO, A. C.; BECKERT, M.; SOUZA, V. Capacitação e desenvolvimento de pessoas. 2. ed. Rio de Janeiro: FGV, 2009.

PAGLIACI, G. E. S.; ALVES, M. N.; CAMARGO, M. L. Treinamento e desenvolvimento de liderança numa organização familiar. In: FEIJÓ, Marianne Ramos; GOULART JÚNIOR, Edward; CAMPOS, Dinael Corrêa; CARDOSO, Hugo Ferrari; CAMARGO, Mário Lázaro. (Orgs.). Primeiros passos na atuação profissional do psicólogo em orientação profissional e de carreira e psicologia organizacional e do trabalho. Araraquara: Letraria, 2019, p. 571 589. Disponível em: <https://www.letraria.net/primeiros-passos-atuacao-profissional/>. Acesso em: 25 set. 2019.

PEREIRA, P. E. J.; SCHNEDE, L.; SILVA, O. F. P. Identificação do perfil do líder para o gerenciamento do projeto de uma nova unidade hospitalar em Santa Catarina. V Singep Simpósio Internacional de Gestão de Projetos, Inovação e Sustentabilidade. 2016. Disponível em: 〈https://singep.org.br/5singep/resultado/142.pdf>. Acesso em: 25 set. 2019.

RODRIGUES, R. R. J.; IMAI, R. Y.; FERREIRA, W. F. Um espaço para o desenvolvimento interpessoal no trabalho. Psicologia em Estudo, Maringá, v. 6, n. 2, p. 123-127, 2001. Disponível em: <http://www.scielo.br/pdf/pe/v6n2/v6n2a17.pdf>. Acesso em: 25 set. 2019.

RODRIGUES, M. S.; ARAÚJO, E. A. S.; RIBEIRO, M. J. F. X.; LEÓN RUBIO, J. M. Habilidades interpessoais nas competências gerenciais e de liderança. In: DEL PRETTE, Z. A. 
P.; SOARES, A. B.; PEREIRA-GUIZZO, C. S.; WAGNER, M. F.; LEME, V. B. R. (Orgs.). Habilidades Sociais: diálogos e intercâmbios entre pesquisa e prática. Novo Hamburgo: Sinopsys, 2015. p. 462-496.

SILVA, L. A. S.; GOULART JÚNIOR, E. A aprendizagem em comportamentos socialmente habilidosos e sua relação com a presença do estresse no contexto de uma empresa júnior. In: FEIJÓ, Marianne Ramos; GOULART JÚNIOR, Edward; CAMPOS, Dinael Corrêa; CARDOSO, Hugo Ferrari; CAMARGO, Mário Lázaro. (Orgs.). Primeiros passos na atuação profissional do psicólogo em orientação profissional e de carreira e psicologia organizacional e do trabalho. Araraquara: Letraria, 2019, p. 90-115. Disponível em: <https://www.letraria.net/primeiros-passos-atuacao-profissional/>. Acesso em: 25 set. 2019.

SILVEIRA, A. M.; GOULART JUNIOR, E. CARDOSO, H. F.; BOLSONI-SILVA, A. Habilidades Sociais Profissionais para gestores de uma IES-Pública: uma proposta de treinamento. In: GOULART JR. E.; CARDOSO, H. F.; FEIJÓ, M. R.; CAMARGO, M. L.; CAMPOS, D. C.(Orgs). Psicologia organizacional e do trabalho e orientação profissional na formação do psicólogo. Araraquara: Letraria, 2016. p. 88-120. Disponível em: <https://www.letraria.net/psicologia-organizacional-e-do-trabalho/>. Acesso em: 25 set. 2019.

SOARES, A. T. N. A comunicação organizacional sob o olhar teórico - contribuições de Niklas Luhmann. In: XXVIII Congresso Brasileiro de Ciências da Comunicação, UERJ. 2005. Disponível em: <http://www.portcom.intercom.org.br/pdfs/122129089031926076271684197005443702826. pdf>. Acesso em: 25 set. 2019.

TURCI, R. H. Feedback - A importância desta técnica na rotina empresarial. Revista Interatividade, v. $1, \quad$ n. 1 , p. 81-89, 2013. Disponível em: <http://www.firb.br/editora/index.php/interatividade/article/view/47>. Acesso em: 25 set. 2019.

VALLE, P. B. Inteligência emocional no trabalho: um estudo exploratório. $48 \mathrm{f}$. Dissertação - (Mestrado profissionalizante em Administração) - Faculdade de Economia e Finanças IBMEC, Rio de Janeiro. 2006. Disponível em: 〈http://livros01.livrosgratis.com.br/cp024778.pdf〉.

Recebido em: 30/09/2019

Aprovado em: 30/11/2019 